\title{
Investigation of partial shading effect on PV array configuration
}

\section{Vinaya Rana* and M.A. Ansari}

Department of Electrical Engineering,

School of Engineering,

Gautam Buddha University, Greater Noida, 201310, India

Email: vinayrana80@gmail.com

Email: ma.ansari@gbu.ac.in

*Corresponding author

\section{Yogesh K. Chauhan}

\author{
Department of Electrical Engineering, \\ Kamla Nehru Institute of Technology (KNIT), \\ Sultanpur, 228118, India \\ Email: chauhanyk@yahoo.com
}

\begin{abstract}
The shading of any PV panel reduces the overall performance of the panel. To overcome these shading effects, the PV panels are connected in different combinations such as series, parallel, series-parallel and total cross tied configurations. These configurations give a better performance during the partial shading. In this paper, four PV panels of $15 \mathrm{~W}$ are analysed for the experimental study and this work has been validated with the help of simulation in MATLAB/Simulink. The performance of the developed model has been analysed by the current-voltage and power-voltage characteristics, maximum power, short circuit current, open circuit voltage, overall electrical efficiency and the fill factor. Among the various configuration methods tested, the total cross tide (TCT) provides maximum power and efficiency as compared to the other configurations with different shading patterns.
\end{abstract}

Keywords: renewable energy; photovoltaic module; PV array configuration; partial shading; PV cell characteristics.

Reference to this paper should be made as follows: Rana, V., Ansari, M.A. and Chauhan, Y.K. (2020) 'Investigation of partial shading effect on PV array configuration', Int. J. Digital Signals and Smart Systems, Vol. 4, Nos. 1/2/3, pp.184-198.

Biographical notes: Vinaya Rana obtained his BTech in Electrical and Electronics Engineering from the AKTU, Lucknow in 2010 and MTech in Power System Engineering from the EED, School of Engineering, Gautam Buddha University, Greater Noida, India in 2013. He is currently working towards his $\mathrm{PhD}$ from the EED, School of Engineering, Gautam Buddha University, Greater Noida, India. 
M.A. Ansari received his BTech in Electrical Engineering in 1998 from the Aligarh Muslim University, India, MTech in Electrical Engineering and PhD in 2001 and 2009 respectively from the Indian Institute of Technology, Roorkee, India. The author has taught in several national and international universities globally. $\mathrm{He}$ is currently associated with the Department of Electrical Engineering, School of Engineering, Gautam Buddha University, Gr. Noida, NCR Delhi, India. His research interests include digital image processing, biomedical instrumentation and control, bio-energy and renewable energy. $\mathrm{He}$ is a senior member of IEEE and has published more than 100 papers in national and international journals and conferences and has guided several MTech dissertations and PhDs.

Yogesh K. Chauhan obtained his BTech in Electrical Engineering from the G.B. Pant University of Agriculture and Technology, Uttarakhand in 1997, MTech from IIT Delhi in 1998 and PhD from the Thapar University, Patiala, Punjab, India in 2010. He is currently working as an Associate Professor in EED, Kamla Nehru Institute of Technology, Sultanpur, India. His research interests include power electronics and drive and renewable energy. He has published many papers in national and international journals and conferences and guided many MTech and PhDs.

\section{Introduction}

The electrical energy consumption is increasing day by day due to high power demand. The conventional sources of energy are in limited quantity and decreasing rapidly. To achieve such energy demand, the non-conventional sources like wind energy, solar photovoltaics (PV), and bio mass play very important role with various advantages such as less pollution, small size, and low maintenance (Bradford, 2006; Weitemeyer et al., 2015). The PV cell converts photon energy into electrical energy and generates power from the PV cell based on solar irradiation and temperature. To find the maximum power point (MPP) of an array, maximum power point techniques (MPPT) are used for different temperature and irradiation. The efficiency of the PV panel is maximum at MPP (Kumar et al., 2018). The PV and IV characteristics of PV panel depends upon the different environmental conditions and irradiation level. The characteristics of solar PV is highly nonlinear in nature. Partial shading and dust accumulation are the main environment condition that reduce the overall performance of the PV panel. Partial shading is formed due to the moving clouds, tree or pole shade, building shadow etc. When partial shading occurs, hotspot arises over the cell, which is shaded. To avoid the shading condition, a bypass diode is used (Verma et al., 2017; Rana et al., 2017). The different configuration is used to extract the maximum power from the PV array under partial shading condition (PSC). Enough literature has been studied the partial shading effect and their possible configuration to obtain the maximum power. In India, usage of solar energy is increasing rapidly, as per different subsidies and government policy. The total installed capacity of solar PV system in 2014 is 2,631.93 MW, which is increasing rapidly. In 2019 it has reached 28,180.71 MW as shown in Figure 1. 
Figure 1 Installed capacity of solar in last six years (see online version for colours)

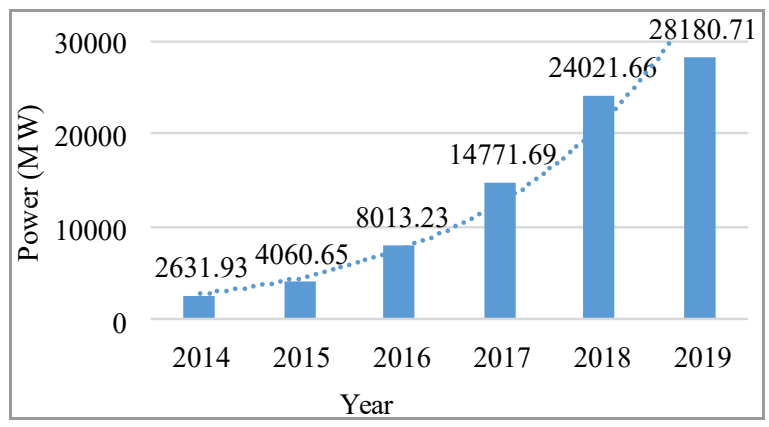

Source: CEA (2019)

\section{Overview of various PV array configurations}

In La Manna et al. (2014), describe the series-parallel (SP) combination to calculate the maximum power in shading conditions and also describe other possible combination such as total cross tied (TCT), honey comb (HC) and bridge link (BL). In Wang and Hsu (2011), examine different configuration using two methods named as piecewise linear parallel branches and Newton-Raphson. However, TCT was the best configuration. In Tian et al. (2013) investigated the effect of bypass diode of a panel and compared it without bypass diode in different shading condition. The simulation study has been analysed to investigate the best configuration under PSC. The different configurations such as series(S), SP, and TCT are investigate under moving cloud shading condition. TCT configuration is superior as compared to other configuration in this study (Jazayeri et al., 2014).

In Pareek et al. (2017), a technique is developed to make the better configuration between PV module that depends upon the shading pattern and shading losses calculation. In Gupta et al. (2016) and Kumar et al. (2014), a MPPT techniques is developed to obtain the maximum power under PSC and also shows the effect of bypass diode. The authors proposed different non-symmetrical puzzle pattern configuration and hybrid configuration for the analysis. In Deline et al. (2013) investigates the non-uniform irradiation effect on the array configurations such as SP, HC, BL and TCT. The energy output is different, when the irradiation is not constant, so the investigation has been done by the Shirzadi et al. (2014) to find the better configuration with low power mismatch effect.

\section{System configuration}

To find the maximum power from an array, the different configurations are represented in Figure 2. The two first configurations represent the series and parallel configurations respectively. The third configuration represents the SP configuration. The TCT configuration is described as fourth configuration. 
Figure 2 Connection diagram of PV array (see online version for colours)

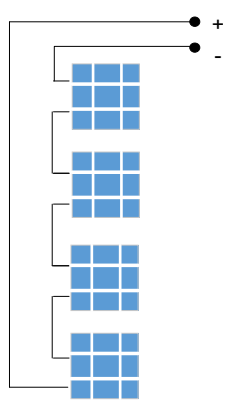

(a) Series Connected (Configuration -1)

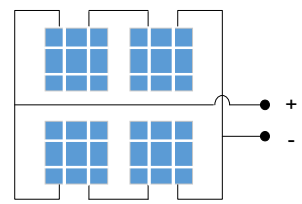

(c) SP Connected (Configuration -3)

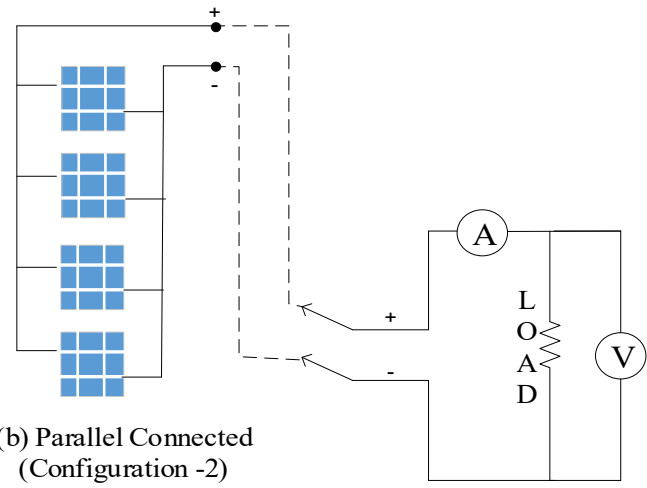

(e) PV-IV Measurement system

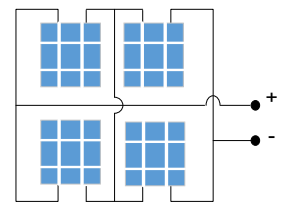

(d) TCT Connected (Configuration -4)

Figure 3 Experimental setup for series configuration (configuration - 1) (see online version for colours)

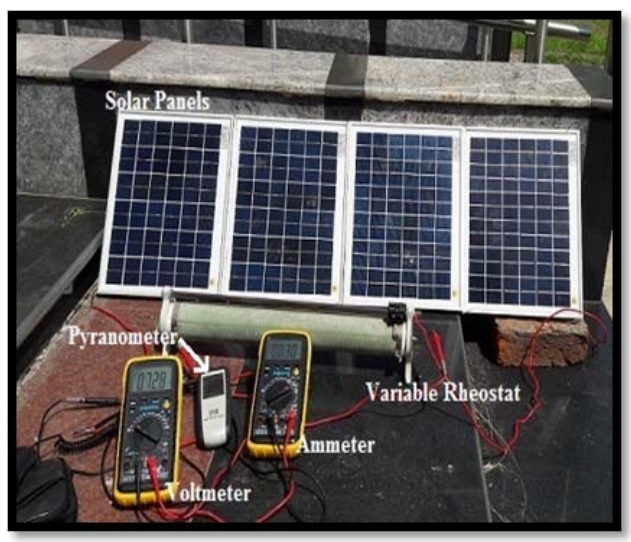

Table 1 Component details and specifications for the experimental setup

\begin{tabular}{lccc}
\hline S. no. & Components & Specification & Quantity \\
\hline 1 & PV panel & $15 \mathrm{~W}$ & 4 \\
2 & Diode & IN 4007 & 4 \\
3 & Digital multi-meter & $0-1,000 \mathrm{~V}, 0-10 \mathrm{~A}$ & 2 \\
4 & Pyranometer & $0-2,000 \mathrm{~W} / \mathrm{m}^{2}$ & 1 \\
5 & Rheostat & $0-220 \Omega, 2.8 \mathrm{~A}$ & 1 \\
\hline
\end{tabular}


An experimental setup developed for this configuration study. The experimental setup is required for following components as shown in Table 1.

The PV panels are connected in series for the experimental study as shown in Figure 3 , and a variable rheostat is used for load. The voltage and current of the configuration are calculated at $300 \mathrm{~W} / \mathrm{m}^{2}$ irradiation.

\section{Modelling of solar PV system}

A PV panel is the combination of PV cells, connected in series and parallel for a specified power output (Gupta et al., 2016). The PV cell is designed as an equivalent circuit and described in Figure 4. The output of the PV cell is described as in equation (1):

$$
I_{\text {cell }}=I_{\text {Photo }}-I_{d}-I_{\text {sh }}
$$

The diode current $\left(I_{d}\right)$ and short circuit current $\left(I_{s h}\right)$ of the PV cell is shown in equation (2) and equation (3):

$$
\begin{aligned}
& I_{d}=I_{0}\left\{\exp \left[\frac{e\left(V_{\text {cell }}+R_{s} I_{\text {sh }}\right)}{A k T_{c}}\right]-1\right\} \\
& I_{\text {sh }}=\left(\frac{V_{\text {cell }}+R_{s} I_{\text {cell }}}{R_{\text {sh }}}\right)
\end{aligned}
$$

Figure 4 PV cell equivalent circuit

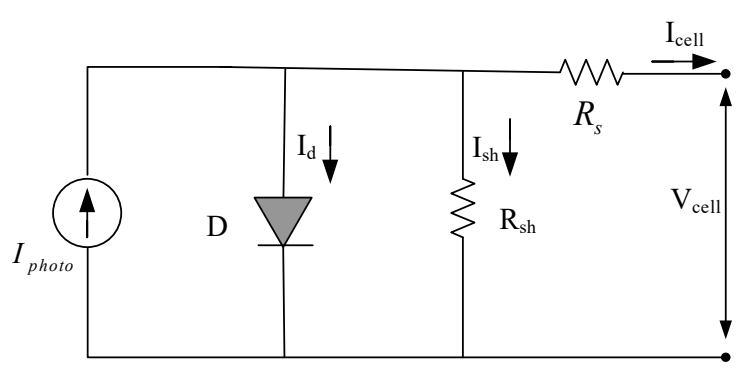

The total output current for a PV cell by rearranging equation (1) to equation (3) is described as in equation (4):

$$
I_{\text {cell }}=I_{\text {photo }}-I_{0}\left\{\exp \left[\frac{e\left(V_{\text {cell }}+R_{s} I_{\text {sh }}\right)}{A k T_{c}}\right]-1\right\}-\left(\frac{V_{\text {cell }}+R_{s} I_{\text {cell }}}{R_{\text {sh }}}\right)
$$

The output voltage of the PV cell is shown as in equation (5):

$$
V_{\text {cell }}=\frac{A k T_{c}}{e} \ln \left(\frac{I_{\text {Photo }}+I_{0}-I_{\text {cell }}}{I_{0}}\right)-R_{s} I_{s}
$$


The open circuit voltage $\left(V_{o c}\right)$ and short circuit current $\left(I_{s c}\right)$ of the PV cell is described as in equation (6) and equation (7) respectively.

$$
\begin{aligned}
& V_{o c}=\frac{A k T_{c}}{e} \ln \left(\frac{I_{\text {Photo }}+I_{0}}{R_{s h}}\right) \\
& I_{s c}=I_{\text {photo }}-I_{0}\left\{\exp \left[\frac{e R_{s} I_{s c}}{A k T_{c}}\right]-1\right\}-\left(\frac{R_{s} I_{s c}}{R_{s h}}\right) \backslash
\end{aligned}
$$

where $T_{c}=$ cell temperature $(\mathrm{K}), e=$ electron charge $\left(1.602 \times 10^{-19} \mathrm{C}\right)$, $I_{\text {photo }}=$ photocurrent (A), $I_{d}=$ diode current (A), $I_{o}=$ reverse saturation current of diode (A), $I_{s c}=$ short circuit current, $R_{s h}=$ short circuit resistance, $R_{s}=$ series resistance, $k=$ Boltzman constant $\left(1.38 \times 10^{-23} \mathrm{~J} / \mathrm{K}\right), A=$ ideality factor (1.2).

The efficiency and fill factor of the PV panel is defined as in equation (8) and equation (9) as:

$$
\begin{aligned}
& \text { Efficiency }=\frac{V_{o c} * I_{s c} * F F}{P_{i n}} * 100 \\
& \text { Fill factor }=\frac{I_{m p p} * V_{m p p}}{I_{s c} * V_{o c}}
\end{aligned}
$$

$I_{m p p}=$ current at MPP, $V_{m p p}=$ voltage at MPP and $P_{i n}$ is the input power of solar module and defined as $P_{\text {in }}=\operatorname{Irr} *$ area of solar cell.

Figure 5 Flow chart of the PV array for different shading patterns and configurations

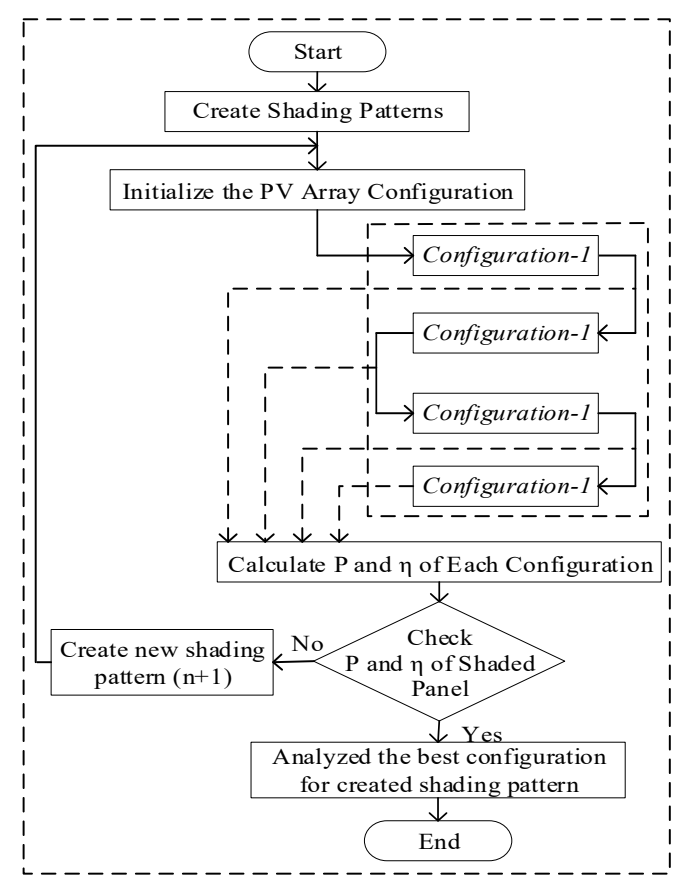




\subsection{Flow chart for different array configurations}

The flow chart of different shading patterns and configurations is shown in Figure 5. In first step the shading pattern is created, then the configuration of the PV array is initialised in the second step. For this analysis, the four different configurations are used such as: series, parallel, SP, and TCT. In third step, each configuration is analysed and then power and efficiency are calculated for the creation of shading pattern. In next step, the power and efficiency are checked form all the configuration for a given shading pattern and find which configuration gives the maximum power for creating shading pattern. If the power is maximum then the process is ending otherwise the new shading pattern is created and then the power and efficiency for the different pattern is analysed.

\section{Results and discussion}

The IV and PV characteristics of the different configurations analysed on the different shading pattern. The PV array is connected in series (S) configuration in first case and then connected in parallel (P) configuration in second case. In third configuration the array is connected in the SP configuration and then connected in TCT in the fourth configuration. The shading pattern of the $\mathrm{S}$ and $\mathrm{P}$ configurations are shown in Table 2 respectively. The performance of the array with different shading has been analysed. Initially, there is no shading on the PV array and then the shading is increased. In this study four panel is used and then the shading is increased one by one as shown in Table 2.

Figure 6 Simulink diagram of series connected PV array (see online version for colours)

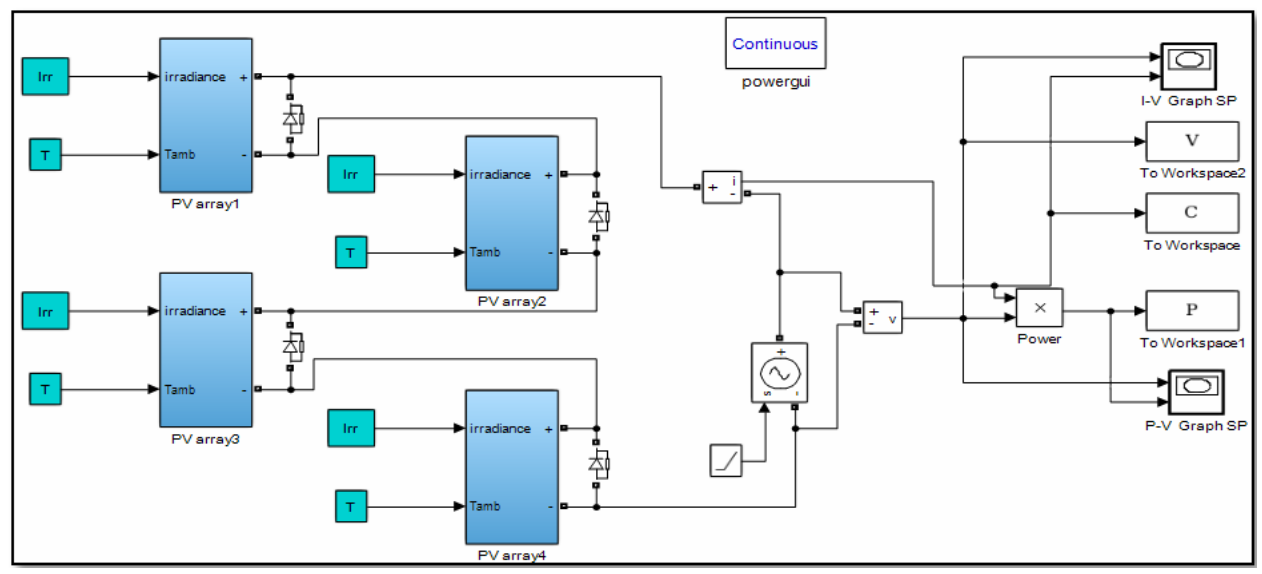

The Simulink-based diagram of the series connection PV array is shown in Figure 6. In this, all panels are connected in series and then voltage, current and power of the configuration is analysed. The efficiency and fill factor of the created pattern is also calculated. 
Table 2 Shading patterns for series and parallel connected panels (see online version for colours)

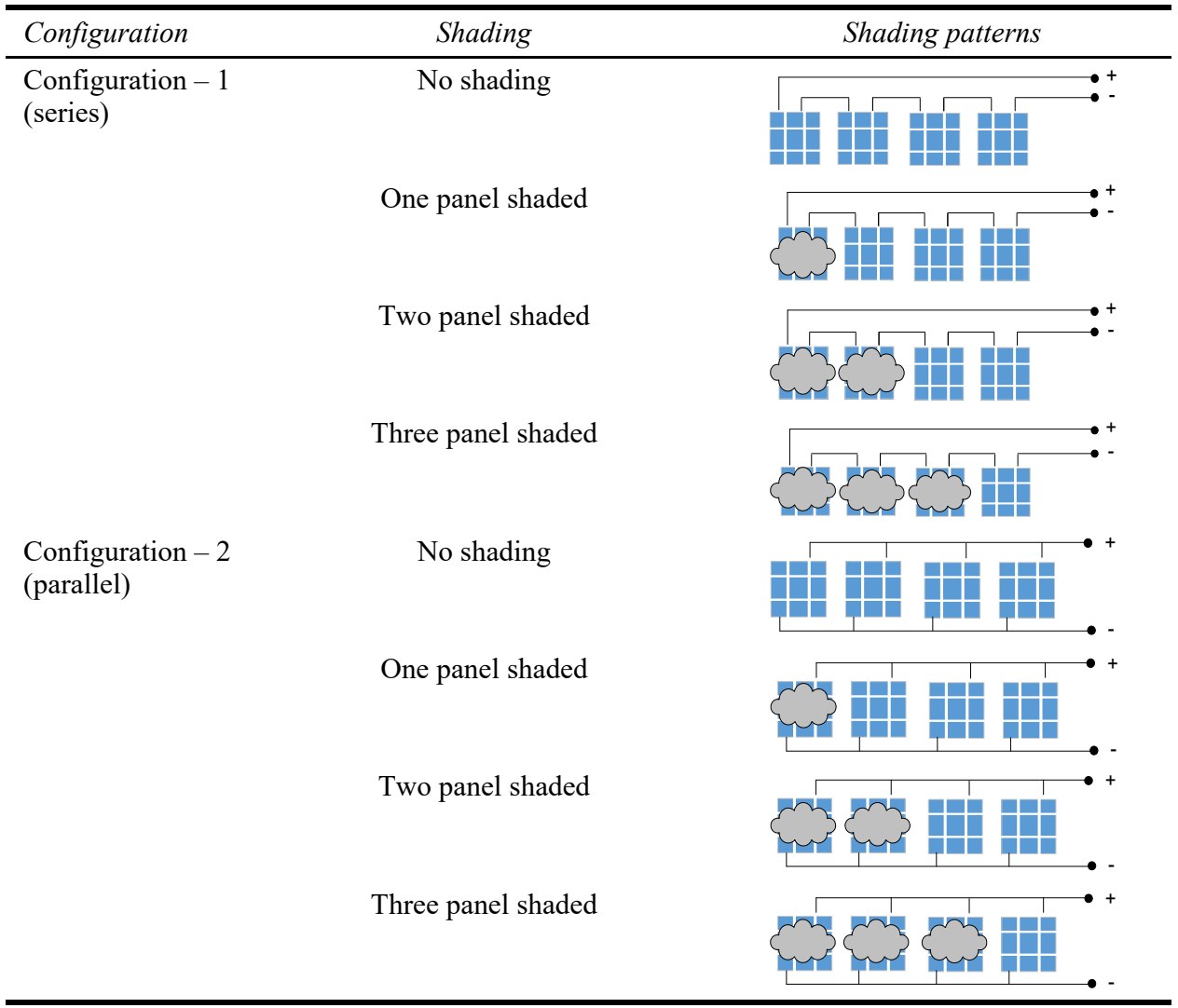

In the SP configuration, the upper and lower group panels are connected in series and then the combination of these connected panels is connected in parallel to this configuration. Initially, there is no shading on the created array configuration. The shading is increased, in pattern 1 only one module of the array is shaded for both the configurations. The shading of the array is created with different patterns as: two panel are shaded in vertical position; two panels are shaded in horizontal pattern and two panels are shaded in diagonal pattern as shown in Figure 7.

Figure 7 Shading patterns for SP configuration, (a) no shade (b) 1 panel shade (c) 2 panel vertical shade (d) 2 panel horizontal shade (e) 2 panel diagonal shade (see online version for colours)

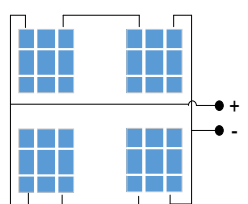

(a)

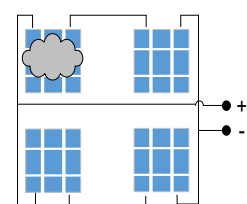

(b)

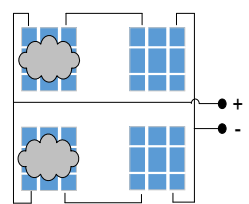

(c)

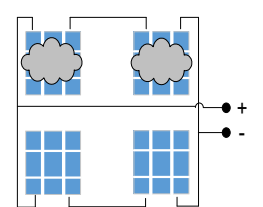

(d)

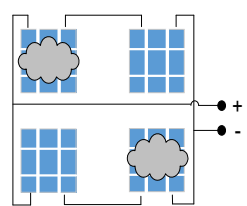

(e) 
In TCT configuration the middle point of the SP configuration is also connected together to find the maximum power during the shading condition. The shading patters are same as the SP configuration and shown in Figure 8. The performance of the array is calculated based on the given shading patterns.

Figure 8 Shading patterns for TCT configuration, (a) no shade (b) 1 panel shade (c) 2 panel vertical shade (d) 2 panel horizontal shade (e) 2 panel diagonal shade (see online version for colours)

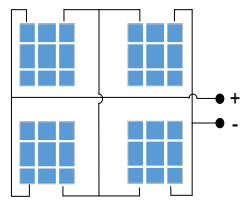

(a)

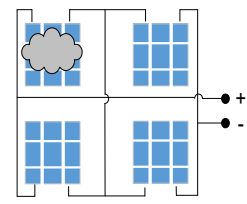

(b)

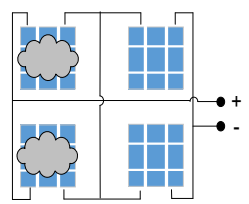

(c)

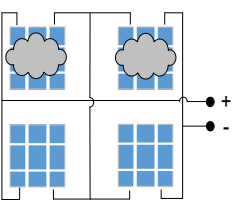

(d)

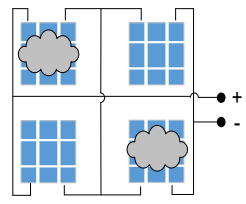

(e)

\subsection{PV and IV characteristics of PV panel in series configuration}

The PV and IV characteristics of series configuration PV array are shown in Figure 9 to Figure 10 of simulation and experimental-based respectively, at the irradiation $300 \mathrm{~W} / \mathrm{m}^{2}$.

Figure 9 PV and IV characteristics of series connected PV array with different shading pattern (simulation-based) (see online version for colours)

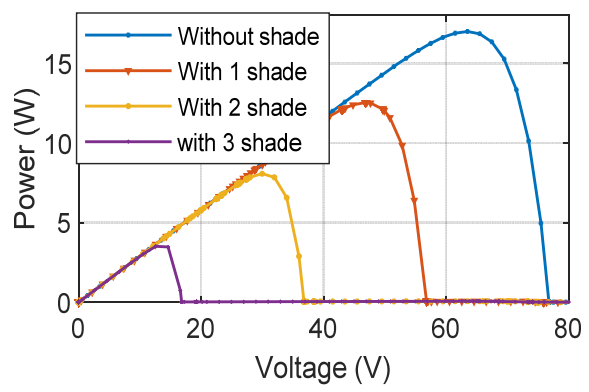

(a)

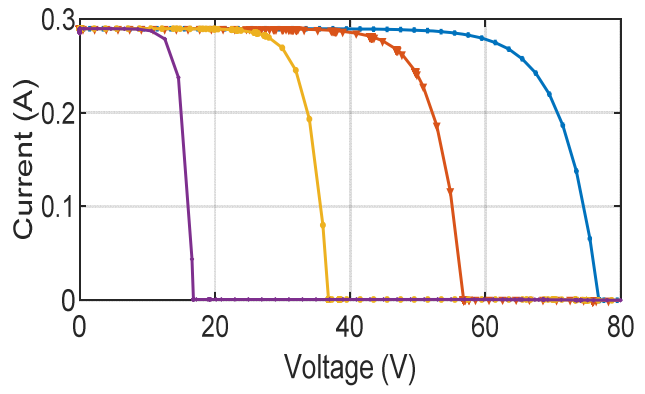

(b)

Figure 10 PV and IV characteristics of series connected PV array with different shading pattern (experimental setup) (see online version for colours)

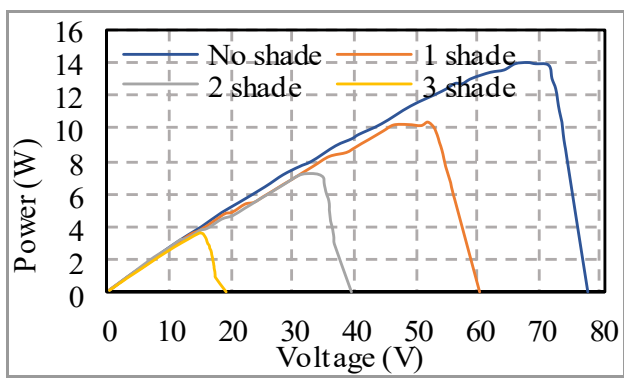

(a)

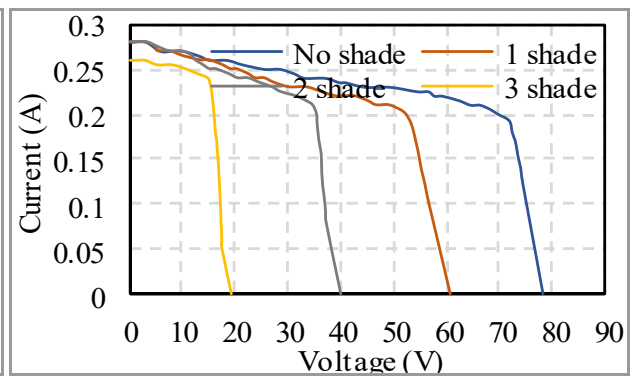

(b) 
Initially, there is no shade on the configuration and the maximum power, fill factor and efficiency in experimental (exp.) based configuration and simulation (sim.) based configuration are $14 \mathrm{~W}, 0.6313,15.948 \%$ and $16.99 \mathrm{~W}, 0.760$ and $19.997 \%$ respectively. As the shading is increased the maximum power and efficiency of the array is decreased. The overall shading effect on the series connected panel is shown in Table 3. The importance of this configuration is that it is beneficial when the shading effect is less the $50 \%$ of the array.

Table 3 Performance parameter of series connected PV panels under different PSC (experimental and simulation)

\begin{tabular}{|c|c|c|c|c|c|c|c|c|}
\hline & \multicolumn{2}{|c|}{ No shade } & \multicolumn{2}{|c|}{1 shade } & \multicolumn{2}{|c|}{2 shades } & \multicolumn{2}{|c|}{3 shades } \\
\hline & Exp. & Sim. & Exp. & Sim. & Exp. & Sim. & Exp. & Sim. \\
\hline $\mathrm{Vm}$ & 68.3 & 63.45 & 52.1 & 47.01 & 33.18 & 29.95 & 15 & 12.58 \\
\hline Im & 0.205 & 0.2679 & 0.20 & 0.2665 & 0.22 & 0.2693 & 0.26 & 0.2786 \\
\hline Pm & 14.0015 & 16.99 & 10.42 & 12.53 & 7.2996 & 8.065 & 3.9 & 3.506 \\
\hline FF & 0.6313 & 0.7603 & 0.6151 & 0.7615 & 0.6550 & 0.7556 & 0.7034 & 0.7225 \\
\hline Efficiency & 15.948 & 19.997 & 12.264 & 14.748 & 8.5918 & 9.4927 & 4.5903 & 4.1266 \\
\hline
\end{tabular}

\section{2 $P V$ and IV characteristics of $P V$ panel in parallel configuration}

The PV and IV characteristics of parallel connected array are shown in Figures 11-12 for simulation and experimental-based study respectively. The shading pattern is increased one by one and it is affected the IV and PV characteristics of the PV array. When all the panels are working together in parallel connected configuration then the maximum power, fill factor and efficiency for the experimental and simulation based are $15.237 \mathrm{~W}$, $0.7013,17.355 \%$ and $16.99 \mathrm{~W}, 0.766,19.35 \%$ respectively without any shading. The power and efficiency of the array is decreased due to increasing the shading patterns. The overall performance parameters of the parallel connected PV array are shown in Table 4.

Figure 11 PV and IV characteristics of parallel connected PV array with different shading pattern (simulation-based) (see online version for colours)

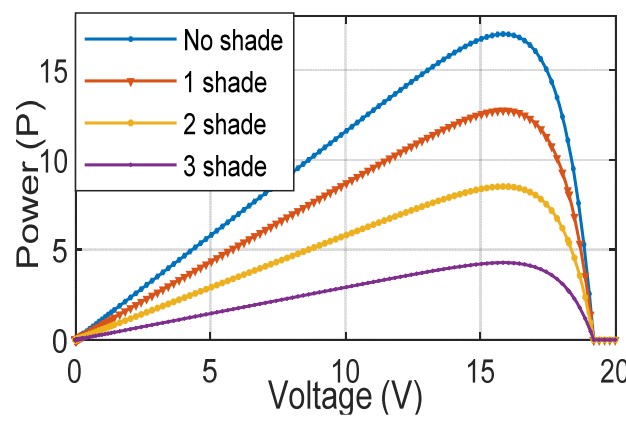

(a)

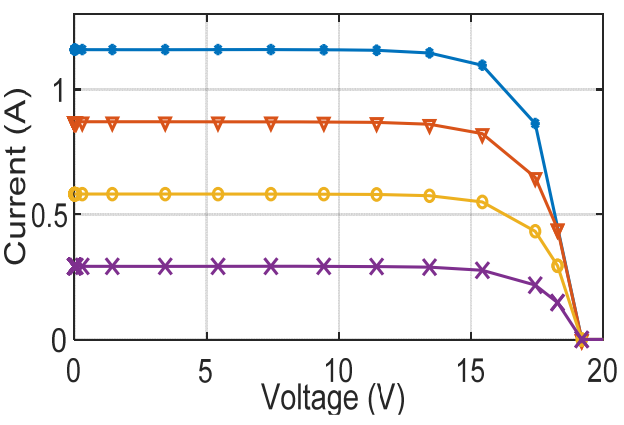

(b) 
Figure $12 \mathrm{PV}$ and IV characteristics of parallel connected PV array with different shading pattern (experimental setup) (see online version for colours)

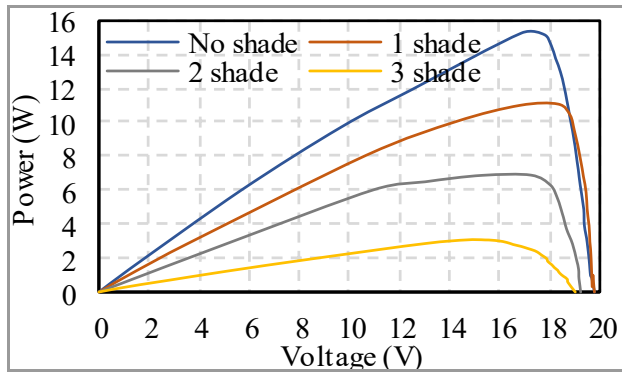

(a)

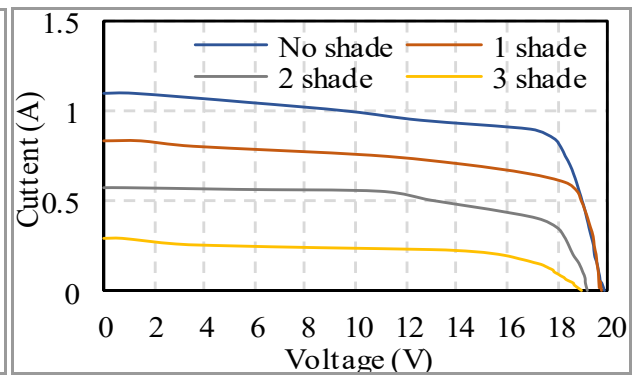

(b)

Table 4 Performance parameter of parallel connected PV panels under different PSC (experimental and simulation)

\begin{tabular}{|c|c|c|c|c|c|c|c|c|}
\hline & \multicolumn{2}{|c|}{ No shade } & \multicolumn{2}{|c|}{1 shade } & \multicolumn{2}{|c|}{2 shades } & \multicolumn{2}{|c|}{3 shades } \\
\hline & Exp. & Sim. & Exp. & Sim. & Exp. & Sim. & Exp. & Sim. \\
\hline $\mathrm{Vm}$ & 16.93 & 15.83 & 18.35 & 15.83 & 17.22 & 15.83 & 15.4 & 15.83 \\
\hline Im & 0.9 & 1.073 & 0.6 & 0.806 & 0.4 & 0.538 & 0.2 & 0.270 \\
\hline $\mathrm{Pm}$ & 15.237 & 16.99 & 11.01 & 12.76 & 6.888 & 8.52 & 3.08 & 4.286 \\
\hline $\mathrm{FF}$ & 0.7013 & 0.7666 & 0.6699 & 0.7679 & 0.6293 & 0.7668 & 0.5789 & 0.7487 \\
\hline Efficiency & 17.355 & 19.352 & 12.959 & 14.534 & 8.1073 & 9.7047 & 3.6252 & 4.8819 \\
\hline
\end{tabular}

Figure 13 PV and IV characteristics of series-parallel connected PV array with different shading pattern (simulation-based) (see online version for colours)

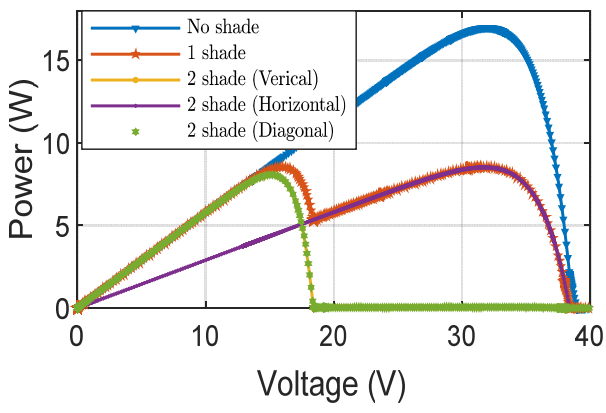

(a)

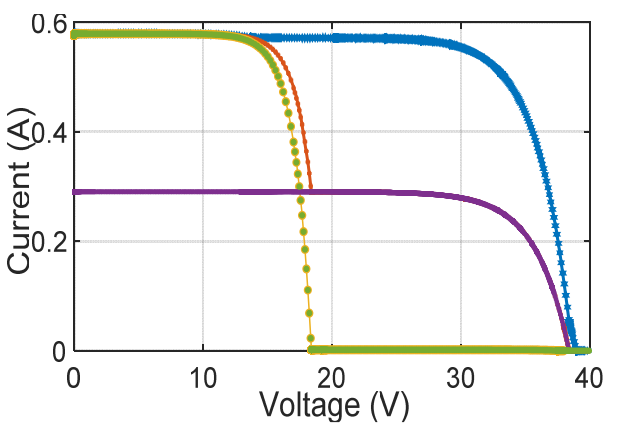

(b)

\subsection{PV and IV characteristics of PV panel in SP configuration}

The PV and IV characteristics of the PV panel connected in series and parallel configuration are shown in Figure 13 based on simulation. The experimental-based array characteristics are shown in Figure 14. In first case, when no shading on the array, the maximum power and efficiency for experimental and simulation are $15.12 \mathrm{~W}, 17.22 \%$ 
and $16.98 \mathrm{~W}, 19.34 \%$ respectively. When the PSC occurs at any panel of the array, then the maximum power, and efficiency is decreased. In this type of configuration, the shading effect is more as compare to another discussed configuration. The maximum power and efficiency of the configuration is decreased as the PSC increase as shown in Table 5. The advantage of this configuration is that the shading effect is wide range providing different shade pattern.

Figure 14 PV and IV characteristics of SP connected PV array with different shading pattern (experimental-based) (see online version for colours)

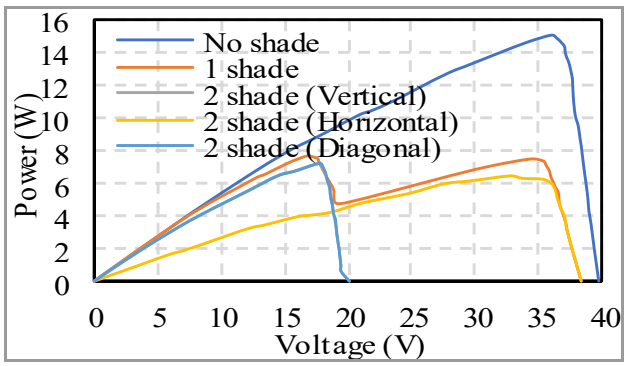

(a)

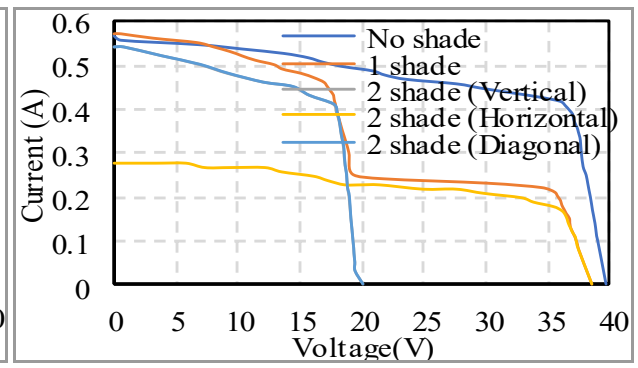

(b)

Table 5 Performance parameter of SP connected PV panels under different PSC (experimental and simulation)

\begin{tabular}{|c|c|c|c|c|c|c|c|c|c|c|}
\hline & \multicolumn{2}{|c|}{ No shade } & \multicolumn{2}{|c|}{1 shade } & \multicolumn{2}{|c|}{2 shade $(V)$} & \multicolumn{2}{|c|}{2 shade $(H)$} & \multicolumn{2}{|c|}{2 Shade (D) } \\
\hline & Exp. & Sim. & Exp. & Sim. & Exp. & Sim. & Exp. & Sim. & Exp. & Sim. \\
\hline $\mathrm{Vm}$ & 36 & 32.14 & 16.9 & 16.01 & 17.6 & 15.01 & 33 & 31.74 & 16.9 & 15.01 \\
\hline Im & 0.42 & 0.5283 & 0.46 & 0.533 & 0.41 & 0.537 & 0.2 & 0.268 & 0.46 & 0.537 \\
\hline $\mathrm{Pm}$ & 15.12 & 16.98 & 7.774 & 8.545 & 7.216 & 8.067 & 6.6 & 8.523 & 7.216 & 8.067 \\
\hline FF & 0.668 & 0.764 & 0.354 & 0.38 & 0.630 & 0.75 & 0.612 & 0.76 & 0.630 & 0.75 \\
\hline Efficiency & 17.22 & 19.34 & 8.85 & 9.73 & 8.21 & 9.18 & 7.51 & 9.70 & 8.21 & 9.18 \\
\hline
\end{tabular}

Figure 15 PV and IV characteristics of series-parallel connected PV array with different shading pattern (simulation-based) (see online version for colours)

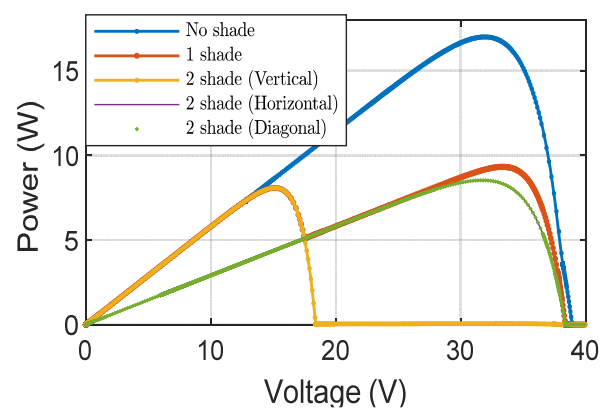

(a)

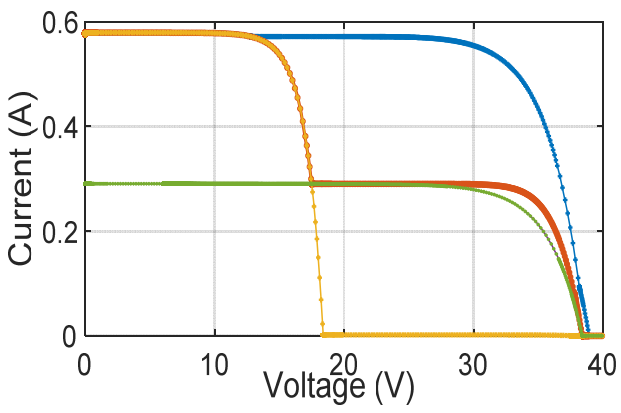

(b) 


\subsection{PV and IV characteristics of PV panel in TCT configuration}

The PV and IV characteristics of the PV panel connected in TCT configuration are shown in Figure 15 by simulation study. The experimental-based IV and PV array characteristics are the same configuration as shown in Figure 16. When no shading on the PV array, the maximum power and efficiency for experimental and simulation study are $15.12 \mathrm{~W}$, $17.22 \%$ and $16.98 \mathrm{~W}, 19.34 \%$ respectively. In this configuration the mid-point is connected so that it gives the maximum power and efficiency in any shading conditions. The different shading patters are created for different study, and the power and efficiency are analysed.

Figure 16 PV and IV characteristics of TCT connected PV array with different shading pattern (experimental-based) (see online version for colours)

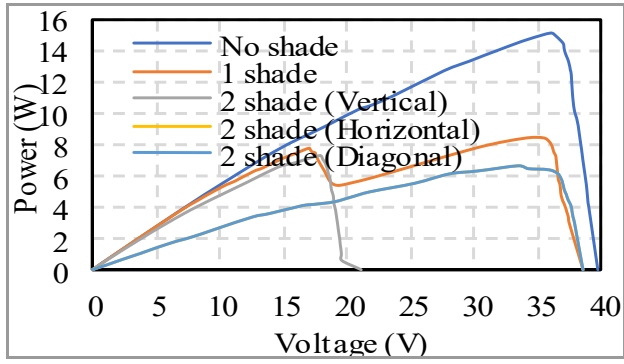

(a)

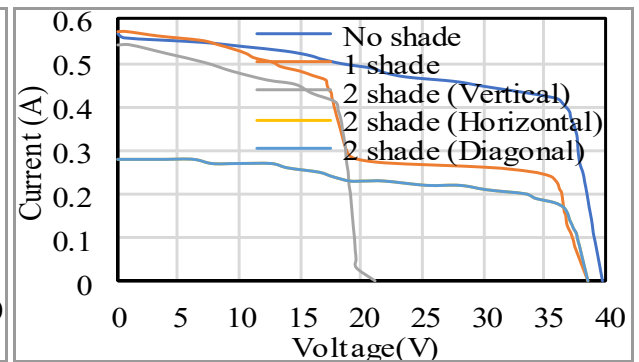

(b)

The total power and efficiency decrease as shading increase as shown in Table 6 . This configuration gives maximum power as all other discussed configuration with same shading pattern.

Table 6 Performance parameter of TCT connected PV panels under different PSC (experimental and simulation)

\begin{tabular}{|c|c|c|c|c|c|c|c|c|c|c|}
\hline & \multicolumn{2}{|c|}{ No shade } & \multicolumn{2}{|c|}{1 shade } & \multicolumn{2}{|c|}{2 shade (V) } & \multicolumn{2}{|c|}{2 shade $(H)$} & \multicolumn{2}{|c|}{2 Shade (D) } \\
\hline & Exp. & Sim. & Exp. & Sim. & Exp. & Sim. & Exp. & Sim. & Exp. & Sim. \\
\hline $\mathrm{Vm}$ & 36 & 32.18 & 35.38 & 33.42 & 17.9 & 15.21 & 33.4 & 31.79 & 33.4 & 31.59 \\
\hline $\operatorname{Im}$ & 0.42 & 0.52 & 0.34 & 0.27 & 0.41 & 0.53 & 0.215 & 0.26 & 0.215 & 0.26 \\
\hline $\mathrm{Pm}$ & 15.12 & 16.98 & 8.49 & 9.314 & 7.33 & 8.067 & 7.18 & 8.523 & 7.18 & 8.523 \\
\hline $\mathrm{FF}$ & 0.668 & 0.764 & 0.386 & 0.419 & 0.641 & 0.756 & 0.620 & 0.766 & 0.620 & 0.766 \\
\hline Efficiency & 17.22 & 19.34 & 9.67 & 10.60 & 8.35 & 9.18 & 8.31 & 9.70 & 8.31 & 9.70 \\
\hline
\end{tabular}

\section{Conclusions}

In this paper, the investigation of partial shading effect on different PV array configurations has been discussed. The investigation has been done on different shading patterns and configurations such as: S, P, SP and TCT. This investigation shows the significant effect of partial shading on power and efficiency of the PV array. When all the PV modules are connected in series, then the maximum power and efficiency is decreased as shading is increased. Initially, the maximum power and efficiency of the PV 
array is $14 \mathrm{~W}$ and $15.94 \%$ respectively and after that three panels are shaded then the maximum power and efficiency decreased and reached up to $3.9 \mathrm{~W}$ and $4.59 \%$ respectively. When all the panels are connected in parallel, then the maximum power and efficiency of the PV array is $15.23 \mathrm{~W}$ and $17.35 \%$ and it decreases as the shading increases and reached up to $3.08 \mathrm{~W}$ and $3.6252 \%$. The maximum power and efficiency for SP configuration is decreased when shading pattern increases, initially the maximum power and efficiency of the configuration is $15.12 \mathrm{~W}$ and $17.22 \%$. When one panel is shaded, the maximum power and efficiency is $7.774 \mathrm{~W}$ and $8.85 \%$. In case of two panels shading then vertical and diagonal shaded patter gives more power as compared to horizontal pattern. In case of TCT configuration, the maximum power and efficiency is same as SP configuration initially. When one panel of the array is shaded, then the maximum power and efficiency is $8.49 \mathrm{~W}$ and $9.67 \%$ which is more than the SP configuration. The horizontal and diagonal both shading effects are same. In first two cases (series and parallel connection), if the shading is between 0 to $50 \%$, the parallel connection provides maximum power and efficiency, when shading is above $50 \%$ the series connected PV array provides maximum power and efficiency as per experimental analysis. The TCT configuration provides more power and efficiency as compared to the SP configuration with different shading patterns. The TCT connected array is more useful for shading cases due to high efficiency and high output power.

\section{References}

Bradford, T. (2006) Solar Revolution: the Economic Transformation of the Global Energy Industry, Vol. 32, MIT Press Books, London.

CEA (2019) http://cea.nic.in/reports/monthly/installedcapacity/2018/installed_capacity-01.pdf.

Deline, C., Dobos, A., Janzou, S. et al. (2013) 'A simplified model of uniform shading in large photovoltaic arrays', Sol. Energy, Vol. 96, pp.274-282.

Gupta, A., Chauhan, Y.K. and Pachauri, R.K. (2016) 'A comparative investigation of maximum power point tracking methods for solar PV system', Sol. Energy, Vol. 136, pp.236-253.

Jazayeri, M., Uysal, S. and Jazayeri, K. (2014) 'A comparative study on different photovoltaic array topologies under partial shading conditions', IEEE PES T\&D Conference and Exposition, Chicago, pp.1-5.

Kumar, B., Chauhan, Y.K. and Shrivastava, V. (2014) 'A comparative study of maximum power point tracking methods for a photovoltaic-based water pumping system', Int. J. Sustain Energy, Vol. 33, No. 4, pp.797-810.

Kumar, K., Ansari, M.A., Varshney, S.K. et al. (2018) 'An efficient technique for power management in hybrid solar PV and fuel cell system', Smart Sci., Vol. 6, No. 3, pp.234-244.

La Manna, D., Li Vigni, V., Riva Sanseverino, E. et al. (2014) 'Reconfigurable electrical interconnection strategies for photovoltaic arrays: a review', Renew. Sustain. Energy Rev., Vol. 33, pp.412-426.

Pareek, S., Chaturvedi, N. and Dahiya, R. (2017) 'Optimal interconnections to address partial shading losses in solar photovoltaic arrays', Sol. Energy, Vol. 155, pp.537-551.

Rana, V., Chauhan, Y.K. and Ansari, M.A. (2017) 'A multilevel inverter fed induction motor driven water pumping system based on solar photovoltaic', 7th India International Conference on Power Electronics (IICPE), Patiala, pp.1-5.

Shirzadi, S., Hizam, H. and Wahab, N.I.A. (2014) 'Mismatch losses minimization in photovoltaic arrays by arranging modules applying a genetic algorithm', Sol. Energy, Vol. 108, pp.467-478. 
Tian, H., Mancilla-David, F., Ellis, K. et al. (2013) 'Determination of the optimal configuration for a photovoltaic array depending on the shading condition', Sol. Energy, Vol. 95, pp.1-12.

Verma, A., Tyagi, A. and Krishan, R. (2017) 'Optimal allocation of distributed solar photovoltaic generation in electrical distribution system under uncertainties', Journal of Electrical Engineering \& Technology, Vol. 12, No. 3, pp.1921-2718.

Wang, Y.J. and Hsu, P.C. (2011) 'An investigation on partial shading of PV modules with different connection configurations of PV cells', Energy, Vol. 36, pp.3069-3078.

Weitemeyer, S., Kleinhans, D., Vogt, T. and Agert, C. (2015) 'Integration of renewable energy sources in future power systems: the role of storage', Renewable Energy, Vol. 75, pp.14-20. 